\title{
Association of interleukin-4 polymorphism with diabetic retinopathy and neuropathy in a Sudanese population
}

\author{
Eltayeb Mohamed Ahmed Tayrab ${ }^{1 *}$ (], Gaafar Mahmoud Gaafar Mahmoud ${ }^{2}$, Hisham Mohamed Abdelrahim³,
} Samia Mahdi Ahmed ${ }^{4}$ and Abdelmonium Elmakki ${ }^{5}$

\begin{abstract}
Background: Interleukin-4 (IL-4) is a multifunctional cytokine; involved in the regulation of immune responses, as well as in the pathogenicity of many diseases, such as diabetes mellitus. Some researchers suggested that IL-4 protects the human pancreatic islet from cytotoxic damages, whereas others suggested some inhibitory actions of IL-4 on pancreatic islets. This study aimed to assess the role of IL-4 genotypes of intron 3 variable number of tandem repeats of the IL-4 gene in diabetic retinopathy and diabetic neuropathy in Sudanese patients with type 2 diabetes mellitus (T2DM). This case-control study was performed in a number of Khartoum state hospitals in Sudan. The study enrolled 181 Sudanese patients, 115 (57 females and 58 males) diagnosed with T2DM and 66 (29 females and 37 males) healthy persons who served as control subjects. Polymerase chain reaction was used for the analysis of IL-4, which was amplified using the following amplification sequence (forward primer: CACGACGTTGTAAAACGACTAGGC TGAAAGGGGGAAAGC; reverse primer: CTGTTCACCTCAACTGCTCC). Biochemical analyses for highly sensitive C- reactive protein (hs-CRP), glycated hemoglobin ( $\mathrm{HbA1c}$ ), fasting plasma glucose, total cholesterol, triglycerides, low-density lipoprotein, and high-density lipoprotein were performed using a chemical analyzer.
\end{abstract}

Results: The study showed that in the diabetic group, 49(42.6\%) had diabetic retinopathy, whereas 7(6.1\%) had diabetic neuropathy. The B1B1 genotype was found to be a higher risk factor for developing diabetic retinopathy than $B 2 B 2[P=0.028$; Odds ratio $(O R)=1.381 ; 95 \%$ confidence interval $(C l) 1.344-9.062]$, whereas the B1B2 genotype was found to be insignificantly associated with retinopathy $(P=0.357 ; O R=1.570 ; 95 \% \mathrm{Cl} 0.654-3.887)$. Furthermore, hsCRP and HbA1C were significantly increased in diabetic neuropathy with IL-4 B1B1 genotype.

Conclusions: IL-4 gene polymorphisms can be good markers for the early identification of risk for diabetic retinopathy and neuropathy in Sudanese people. The hs-CRP and HbA1c in diabetic patients with IL-4 B1B1 genotype may be predisposition predictors of diabetic neuropathy.

Keywords: Interleukin-4, Intron 3 VNTR, Type 2 diabetes mellitus, Retinopathy, Neuropathy, Sudan

\section{Background}

Interleukins are a type of cytokines produced by somatic cells as well as by leukocytes (Justiz and Qurie 2020). Interleukins play essential roles in the pathogenicity of

\footnotetext{
*Correspondence: eltayebtayrab@gmail.com

1 Department of Chemical Pathology, Faculty of Medical Laboratory

Sciences, The National Ribat University, P.O. Box 55, Khartoum, Sudan

Full list of author information is available at the end of the article
}

many diseases (Balasubramanian et al. 2006) and have both autocrine and paracrine functions (Justiz and Qurie 2020). First identified in 1980, interleukin-4 (IL-4) is a multifunctional cytokine mainly produced by $\mathrm{T}$ cells, mast cells, eosinophils, and basophils (LaPorte et al. 2008). IL-4 is a potent prototypic member of the Th2type cytokine subset that acts as a mediator for proinflammatory chemokines (Kuran et al. 2019; Al-Ayed et al. 2019). IL-4 suppresses adipocyte differentiation and thus 
enhances lipolysis (Tsao et al. 2014). It regulates the proliferation of macrophages, lymphocytes, and endothelial cells as well as apoptosis and the expression of many genes (LaPorte et al. 2008). IL-4 also inhibits tumor growth by exhibiting anti-angiogenic effects (Balasubramanian et al. 2006) and is involved in isotype switching from immunoglobulins (Kuran et al. 2019). Moreover, IL-4 regulates immune responses inducing helper $\mathrm{T}$ cell differentiation (Arababadi et al. 2012). Type 2 diabetes mellitus (T2DM) is a multifactorial genetic disease, characterized by different environmental and genetic causes (Cilensek et al. 2012). T2DM induces oxidative stress associated with various metabolic disturbances (Kundu el al. 2014; Pasnoor et al. 2013). Free radicals produced from T2DM damage cellular enzymes, increase lipid peroxidation, and promote insulin resistance, and lead to the development of diabetic complications (Maritim et al. 2003). The major complications of T2DM are due to the damage of small blood vessels including the eyes, nerves, and kidneys (Rosenberger et al. 2020). Diabetic retinopathy and diabetic neuropathy are the most important complications of T2DM (Pasnoor et al. 2013; MadsenBouterse and Kowluru 2008). Diabetic retinopathy is a severe microvascular complication of diabetes (Stamenkovic et al. 2018) and is also the most severe ocular disease (Madsen-Bouterse and Kowluru 2008). Like glaucoma, diabetic neuropathy is characterized by the quick degeneration of retinal ganglion cells and is a leading cause of acquired blindness (Stamenkovic et al. 2018).

Diabetic neuropathy is a multifactorial interaction of genetic, biological, and psychosocial factors (Hebert et al. 2017). Diabetic neuropathy affects $50 \%$ of patients with diabetes (Pasnoor et al. 2013; Prabodha et al. 2018). Diabetic neuropathy symptoms include tingling, numbness and altered pain sensation, which may damage the patient's skin (Rosenberger et al. 2020). However, proximal diabetic neuropathy may lead to painful muscle atrophy, weakness, and cognitive defects and disabilities (Oyenihi et al. 2015).

\section{Aim of the study}

The aim of this research was to assess the role of IL- 4 genotypes of intron 3 variable number of tandem repeats (VNTR) of the IL-4 gene in diabetic retinopathy and neuropathy in Sudanese patients with T2DM. VNTR was associated with IL-4 production (Nakashima et al. 2002).

\section{Methods}

\section{Patient selection and data collection}

This case-control study was conducted at Ribat University Hospital and Ahmed Gasim Fadul Hospital for Cardiac Surgery and Renal Transplantation in Khartoum, Sudan, in the period from 1 September 2015 to 30 May
2019. A total of 115 Sudanese patients suffering from T2DM (57 females and 58 males) and 66 healthy persons as control subjects ( 29 females and 37 males) were enrolled.

\section{Ethical considerations}

Ethical approval was obtained from the Ethics Research Committee of National Ribat University (Ph.D/medical-lab/2015/no:1). Written consent was obtained from all patients. Clinical and sociological data were collected through questionnaires conducted by a physician.

\section{DNA extraction}

Approximately $2.5 \mathrm{~mL}$ venous blood was collected from each patient and mixed with ethylenediaminetetraacetic acid (EDTA) anticoagulant. Genomic DNA was isolated from EDTA whole blood using Generation DNA purification capture column kit (Analytica Jena, Berlin Germany) according to manufacturer's instructions and then stored at $-20^{\circ} \mathrm{C}$.

\section{Polymerase chain reaction for interleukin-4}

IL-4 was amplified using the following amplification sequence (forward primer: CACGACGTTGTAAAA CGACTAGGCTGAAAGGGGGAAAGC; reverse primer: CTGTTCACCTCAACTGCTCC) (Tong et al. 2013).

The region that contains the VNTR of 70 bp within the IL-4 intron-3 was amplified by polymerase chain reaction (PCR). Primers were prepared using $10 \mu \mathrm{L}$ primer added to $90 \mu \mathrm{L}$ sterile de-ionized water. Forward and reverse primers were prepared in separate Eppendorf tubes. The PCR mixture was prepared by adding $0.5 \mu \mathrm{L}$ forward primer, $0.5 \mu \mathrm{L}$ reverse primer of each gene, and $17 \mu \mathrm{L}$ sterile water to a PCR Premix tube before finally adding $2 \mu \mathrm{L}$ DNA of patient sample for a total volume of 20 $\mu \mathrm{L}$. The experiment consisted of DNA in $0.5 \mathrm{~mL}$ mixture (PCR Premix tube, Intron Biotechnology). Using PCR for all subjects, amplification was performed by initial denaturation at $95{ }^{\circ} \mathrm{C}$ for $10 \mathrm{~min}$, followed by 30 cycles at $95{ }^{\circ} \mathrm{C}$ for $30 \mathrm{~s}, 60{ }^{\circ} \mathrm{C}$ for $30 \mathrm{~s}, 72^{\circ} \mathrm{C}$ for $30 \mathrm{~s}$, and a final extension of $72{ }^{\circ} \mathrm{C}$ for $7 \mathrm{~min}$. The amplified products were further analyzed by electrophoresis in a $1.5 \%$ agarose gel and stained with $0.5 \mathrm{mg} / \mathrm{mL}$ (concentration) ethidium bromide. Approximately $2 \mu \mathrm{L}$ of 100 bp ladder and $10 \mu \mathrm{L}$ of PCR product were loaded on gel.

\section{Biochemical methods}

Biochemical analyses for fasting plasma glucose, total cholesterol, triglycerides, low-density lipoprotein (LDL), and high-density lipoprotein (HDL) were performed using a fully automated chemical analyzer (Mindray BS-380). But highly sensitive C-reactive protein (hs-CRP) 
and glycated hemoglobin $(\mathrm{HbA1c})$ were measured with a chemistry analyzer (COBAS Integra 400 plus).

\section{Statistical methods}

SPSS version 20 was used to calculate the means, standard deviations, probability, genotypes distribution and P-values. Odds ratio (OR) was assessed by Chi-squared test with 95\% confidence intervals. One-way analysis of variance (ANOVA) was used for comparisons between groups. Statistical significance was considered when $P<0.05$.

\section{Results}

In the diabetic group, the mean age was $(53.60 \pm 7.822$ years), the mean duration period of the disease was (10.080 \pm 7.044 years), and the mean body mass index was $(27.76 \pm 3.82) \mathrm{kg} / \mathrm{m}^{2}$.

Intron 3 VNTR of IL-4 gene on the electrophoresis gel was identified as the following IL-4 genotypes: B1B1, $\mathrm{B} 2 \mathrm{~B} 2$, and B1B2, which were identified as the two repeats (183 bp allele, and three repeats (253 bp allele) of VNTR polymorphism and expressed as $\mathrm{B} 1$ and $\mathrm{B} 2$, respectively. Homozygote genotypes were expressed as (B1B2), in the electrophoresis gel. The biochemical parameters studied according to IL-4 genotype distribution included glucose, HbA1c, hs-CRP, total cholesterol, triglycerides, HDL, and LDL. ANOVA revealed only statistically insignificant differences among genotypes in glucose, total cholesterol, triglycerides, HDL, LDL, and body mass index (P-values $=0.513,0.559,0.458,0.237$, and 0.242 , respectively). However, there were significant increases in $\mathrm{HbA1c}$ and hs-CRP levels in the $\mathrm{B} 1 \mathrm{~B} 1$ genotype $(\mathrm{P}=0.003$ and 0.001 , respectively), as shown in Table 1.

The frequencies of IL-4 genotypes in T2DM patients and the healthy control group were $58(50.4 \%)$ and 34 (51.5\%), respectively, for B2B2; 27 (23.5\%) and 5 (7.6\%), respectively, for B1B1; and 30 (26.1\%) and 27 (40.9\%), respectively, for $\mathrm{B} 1 \mathrm{~B} 2$. The distributions of the IL-4 genotypes with risk analysis of T2DM showed that the B1B1 genotype was a high-risk factor for T2DM $(\mathrm{P}=0.028$; $\mathrm{OR}=3.166$; $95 \%$ confidence interval $(\mathrm{CI})$ 1.114-8.991), whereas the $\mathrm{B} 1 \mathrm{~B} 2$ genotype was protective $(\mathrm{P}=0.233$ : $\mathrm{OR}=0.651 ; 95 \%$ CI $0.333-1.273$ ) (Table 2).

The distributions of IL-4 genotypes with risk analysis of diabetic retinopathy showed that; the B1B1 genotype was a high-risk factor for diabetic retinopathy $(\mathrm{P}=0.011$; $\mathrm{OR}=1.381 ; 95 \%$ CI 1.344-9.062), whereas the B1B2 genotype was insignificantly associated with retinopathy $(\mathrm{P}=0.357 ; \mathrm{OR}=1.570 ; 95 \% \mathrm{CI}$ 0.654-3.887) (Table 3). Furthermore, the prevalence in the diabetic group for diabetic retinopathy and diabetic neuropathy was 49 (42.6\%) and 7(6.1\%), respectively (Figs. 1, 2).

Comparisons of the mean values of the biochemical parameters and body mass index in Sudanese patients

Table 1 Comparison of biochemical parameters of interleukin-4 genotypes in type 2 diabetes mellitus $(n=115)$

\begin{tabular}{|c|c|c|c|c|}
\hline Genotypes & $B 1 B 1(n=27)$ & B2B2 $(n=58)$ & $B 1 B 2(n=30)$ & $P$ value \\
\hline Glucose (mg/dL) & $189.11 \pm 79.123$ & $179.53 \pm 86.665$ & $165.53 \pm 54.910$ & 0.513 \\
\hline $\mathrm{HbA1c}(\%)$ & $9.637 \pm 2.2937$ & $8.097 \pm 1.7053$ & $8.170 \pm 2.1552$ & 0.003 \\
\hline hs-CRP (mg/L) & $49.734 \pm 9.593$ & $9.852 \pm 2.3632$ & $2.073 \pm 1.379$ & 0.001 \\
\hline Total cholesterol (mg/dL) & $218.48 \pm 58.392$ & $206.72 \pm 60.971$ & $202.13 \pm 55.883$ & 0.559 \\
\hline Triglycerides (mg/dL) & $150.67 \pm 72.568$ & $141.76 \pm 62.645$ & $130.67 \pm 41.207$ & 0.458 \\
\hline $\mathrm{HDL}(\mathrm{mg} / \mathrm{dL})$ & $41.66 \pm 8.777$ & $44.41 \pm 9.280$ & $45.67 \pm 8.872$ & 0.237 \\
\hline $\mathrm{LDL}(\mathrm{mg} / \mathrm{dL})$ & $100.96 \pm 37.892$ & $114.72 \pm 41.443$ & $105.03 \pm 29.417$ & 0.242 \\
\hline BMI (kg/m2) & $28.245 \pm 4.4244$ & $27.919 \pm 3.6516$ & $27.033 \pm 3.6172$ & 0.450 \\
\hline
\end{tabular}

Comparisons were performed by one-way analysis of variance.

Significant differences between groups $(P<0.05)$. HbA1c, glycated hemoglobin; hs-CRP, highly sensitive $C$-reactive protein; HDL, high- density lipoprotein; LDL, lowdensity lipoprotein; BMI, body mass index

Table 2 Distribution of interleukin-4 genotypes in type 2 diabetes mellitus and control groups and risk analysis

\begin{tabular}{lccll}
\hline Genotype & T2DM, $\mathbf{n}(\%)$ & Control, $\mathbf{n}(\%)$ & $\mathbf{X}^{\mathbf{2}}$ & OR (95\% Cl) \\
\hline B2B2 & $58(50.4 \%)$ & $34(51.5 \%)$ & & 1.0 Reference \\
B1B1 & $27(23.5 \%)$ & $5(7.6 \%)$ & 5.011 & $3.166(1.114-8.991)$ \\
B1B2 & $30(26.1 \%)$ & $27(40.9 \%)$ & 1.578 & $0.651(0.333-1.273)$ \\
Total & $115(100.0)$ & $66(100.0)$ & & 0.028 \\
\hline
\end{tabular}

Comparisons were performed by Chi-squared test

Significant differences between groups $(\mathrm{P}<0.05)$. T2DM, type 2 diabetes mellitus; OR, odds ratio; $\mathrm{Cl}$, confidence interval 
Table 3 Distribution of interleukin-4 genotypes in Sudanese patients with type 2 diabetes mellitus and risk analysis of developing diabetic retinopathy

\begin{tabular}{lllll}
\hline Genotypes & $\begin{array}{l}\text { Presence of retinopathy, } \\
\mathbf{n}(\%)\end{array}$ & $\begin{array}{l}\text { Absence of retinopathy, } \\
\mathbf{n}(\%)\end{array}$ & $\mathbf{X}^{\mathbf{2}}$ & OR (95\% Cl) \\
\hline B2B2 & $19(38.8 \%)$ & $39(59.0 \%)$ & & 1 Reference \\
B1B1 & $17(34.7 \%)$ & $10(15.2 \%)$ & 3.489 & $1.381(1.344-9.062)$ \\
B1B2 & $13(26.5 \%)$ & $17(25.8 \%)$ & 0.956 & $1.570(0.654-3.887)$ \\
Total & 49 & 66 & 115 & \\
\hline
\end{tabular}

Comparisons were performed by the Chi-squared test

Significant differences between groups $(\mathrm{P}<0.05)$. OR, odds ratio; $\mathrm{Cl}$, confidence interval

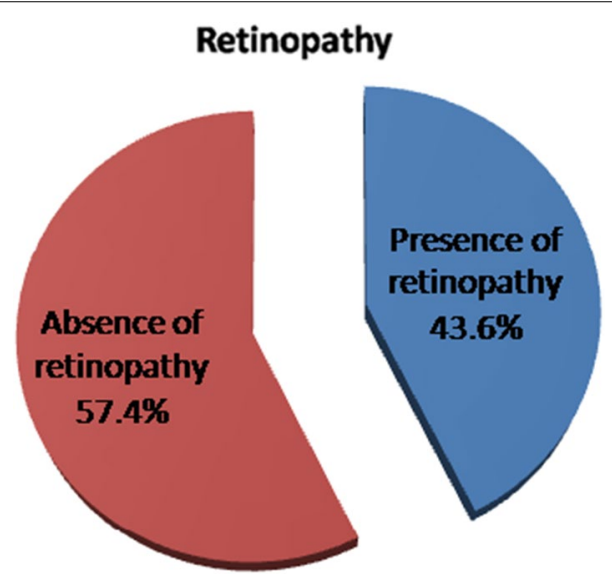

Fig. 1 The frequency of diabetic retinopathy among Sudanese patients with type 2 diabetes mellitus (expressed in percentages, $n=115)$

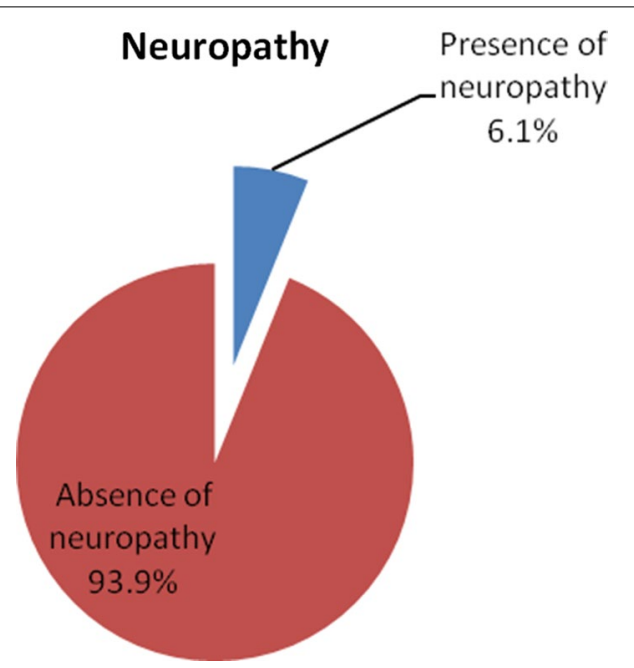

Fig. 2 The frequency of diabetic neuropathy among Sudanese patients with type 2 diabetes mellitus (expressed in percentages, $n=115)$ with T2DM regarding the presence and absence of diabetic retinopathy and diabetic neuropathy are shown in Tables 4 and 5 , respectively.

\section{Discussion}

Many studies (Maritim et al. 2003; Rosenberger et al. 2020) have investigated the role of immunological mechanisms in the pathogenicity of diabetic retinopathy and diabetic neuropathy. IL- 4 is known as a type of chemokine and cytokine and acts as a mediator for inflammatory or proinflammatory functions. Inflammation plays a major role in increasing the production of free radicals and oxidative stress in the body. Poor glycemic control and oxidative stress most likely lead to diabetic complications, such as diabetic retinopathy and neuropathy. In the present study, the findings on the frequencies of IL-4 genotypes in T2DM (Table 2) suggest that the susceptibility to develop T2DM was three-folds higher in patients with IL-4 B1B1 genotype than those with IL-4 B2B2 genotype. Although genetic factors play a role in diabetic retinopathy, uncontrolled hyperglycemia is a critical risk factor in its pathogenesis (Pradhan et al. 2016). The findings of the present study further demonstrate that certain IL-4 genotypes particularly predispose toward diabetic retinopathy. These findings are contrary to a report by (Završnik et al. 2018) who did not find an association between IL-4 and diabetic complications in a Slovenian study of Caucasian patients with T2DM.

On the contrary, our study findings on the frequency of diabetic retinopathy (Figs. 1,2) are consistent with a report by (Ciulla et al. 2003). Furthermore, Stamenkovic et al. 2018 reported that diabetic retinopathy was estimated at $50 \%$ in patients with diabetes. The prevalence of diabetic retinopathy in American people with T2DM, regardless of racial difference, is $28.5 \%$ (Yue $\mathrm{Li}$ et al. 2018), which is much lower than in Sudanese with T2DM.

Diabetic neuropathy is another common complication of T2DM. As reported by (Yeong et al. 2019), IL-4 
Table 4 Comparisons of biochemical parameters and body mass index in Sudanese with type 2 diabetes mellitus with regards the presence or absence of retinopathy $(n=115)$

\begin{tabular}{lccc}
\hline Parameters & $\begin{array}{l}\text { Presence of Retinopathy } \\
(\mathbf{n = 4 9 )}\end{array}$ & $\begin{array}{l}\text { Absence of Retinopathy } \\
\text { (n=66) }\end{array}$ & $\begin{array}{c}\text { P value } \\
\text { Glucose (mg/dL) }\end{array}$ \\
HbA1c (\%) & $164.35 \pm 46.166$ & $188.36 \pm 93.474$ & 0.073 \\
hs-CRP (mg/L) & $8.516 \pm 2.2974$ & $8.448 \pm 1.8865$ & 0.862 \\
Total cholesterol (mg/dL) & $21.186 \pm 6.889$ & $14.216 \pm 3.520$ & 0.481 \\
Triglycerides (mg/dL) & $213.51 \pm 63.143$ & $204.41 \pm 55.675$ & 0.415 \\
HDL (mg/dL) & $129.98 \pm 56.556$ & $149.11 \pm 62.239$ & 0.093 \\
LDL (mg/dL) & $44.92 \pm 8.691$ & $43.48 \pm 9.405$ & 0.403 \\
BMl (kg/m2) & $113.35 \pm 41.474$ & $105.71 \pm 35.134$ & 0.288 \\
\hline
\end{tabular}

Independent t-test was used

$\mathrm{P}<0.05$ was considered significant

HbA1c, glycated hemoglobin; hs-CRP, highly sensitive C-reactive protein; HDL, high- density lipoprotein; LDL, low-density lipoprotein; BMI, body mass index

Table 5 Comparisons of biochemical parameters and body mass index in Sudanese with type 2 diabetes mellitus with regards the presence or absence of neuropathy $(n=115)$

\begin{tabular}{llcl}
\hline & $\begin{array}{l}\text { Presence of } \\
\text { Neuropathy } \\
(\mathbf{n = 7})\end{array}$ & $\begin{array}{l}\text { Absence of } \\
\text { Neuropathy } \\
(\mathbf{n}=108)\end{array}$ & P value \\
\hline Glucose (mg/dL) & $175.57 \pm 61.722$ & $178.30 \pm 78.749$ & 0.929 \\
HbA1c (\%) & $11.900 \pm 2.325$ & $8.225 \pm 1.874$ & 0.000 \\
hs-CRP (mg/L) & $18.006 \pm 5.369$ & $4.543 \pm 1.618$ & 0.011 \\
Total cholesterol (mg/ & $227.86 \pm 37.547$ & $207.02 \pm 59.897$ & 0.366 \\
$\quad$ dL) & $129.71 \pm 51.896$ & $141.69 \pm 61.28$ & 0.613 \\
Triglycerides (mg/dL) & $41.09 \pm 1.577$ & $44.29 \pm 9.349$ & 0.005 \\
HDL (mg/dL) & $98.71 \pm 48.335$ & $109.63 \pm 37.397$ & 0.464 \\
LDL (mg/dL) & $24.27 \pm 5.338$ & $27.995 \pm 3.226$ & 0.112 \\
BMl (kg/m2) & & &
\end{tabular}

Independent t-test was used

$\mathrm{P}<0.05$ was considered significant. $\mathrm{HbA} 1 \mathrm{c}$, glycated hemoglobin; hs-CRP, highly sensitive $\mathrm{C}$-reactive protein; $\mathrm{HDL}$, high- density lipoprotein; $\mathrm{LDL}$, low-density

lipoprotein; BMI, body mass index

plays a critical role in neurodegeneration and neuronal death by regulating oxidative stress in neurodegenerative diseases. While it is known that diabetes mellitus induces oxidative stress with various metabolic disturbances, the exact metabolic pathway is unclear, but the most commonly proposed one is enhanced cellular oxidative stress (Pang et al. 2020). In T2DM, hyperglycemia induces overproduction of reactive oxygen species, leading to damage to lipids, proteins, and DNA, which is key to the pathogenesis of diabetic neuropathy (Kasznicki et al. 2012). Genetic susceptibility and oxidative stress may have a role in the occurrence of T2DM and diabetic neuropathy (Stoian et al. 2015). In this study, the frequency of neuropathy in Sudanese with type $2 \mathrm{DM}$ is $(6.1 \%)$. While the prevalence of diabetic neuropathy may reach as much as $67 \%$ according to a systemic review (Zhao et al. 2019), the present finding of $6.1 \%$ prevalence indicates that diabetic neuropathy is significantly lower in Sudanese with T2DM. While the mechanism of diabetic neuropathy is still not fully understood, the metabolic issues involving elevated $\mathrm{HbA} 1 \mathrm{c}$ as revealed by this study indicates a significant association between diabetic neuropathy and increased HbA1c (Table 5), which is in agreement with previous reports (Kasznicki et al. 2012; Themistocleous et al. 2016).

Further findings in the present study include a significant increase in HbA1c and hs-CRP levels in patients with a B1B1 genotype, which affirm the report (Acharya et al. 2016), on the significant association of HbA1c with T2DM. The IL-4 B1B1 genotype may thus be a good predictor of the onset of diabetic retinopathy.

\section{Conclusions}

Many genetic causes are associated with the development of diabetic complications. The IL-4 gene polymorphism can be a good marker for early identification in Sudanese people at risk of diabetic retinopathy and neuropathy. The IL-4 B1B1 genotype may be an accurate predictor for the onset of diabetic retinopathy. This study is a conceptual investigation, and larger-scale future studies are needed to establish the exact role of IL-4 in diabetic retinopathy.

\section{Abbreviations}

IL-4: Interleukin-4; T2DM: Type 2 Diabetes Mellitus; hs-CRP: C- reactive Protein; HbA1c: Glycated Hemoglobin; VNTR: Variable Number of Tandem Repeats;

EDTA: Ethylenediaminetetraacetic Acid; PCR: Polymerase Chain Reaction; SPSS: Statistical Package for Social Sciences; ANOVA: One-way Analysis Variance. 


\section{Acknowledgements}

The authors would like to thank and acknowledge the great help of the department of the Internal Medicine (Ribat University Hospital), also we appreciate the help of Ahmed Gasim Fadul Hospital for Cardiac Surgery \& Renal Transplant Center, we also appreciate the assistance of the molecular laboratory (College of Veterinary Medicine, Sudan University of Science and Technology). Finally, we appreciate the technical assistance of Dr.Ehab ELnour Mossaad and Mrs. Suhair Reyhan, Khartoum, Sudan.

\section{Authors' contributions}

ET prepared the research project, shared sample collection, did data analysis, wrote the paper, shared the consumables. He was the main supervisor of the research. GM prepared the project proposal, collected the samples, did the lab work, did data analysis, wrote the paper and shared the consumables. HA prepared the project proposal, did the clinical work, checked the patients and controls, did data analysis and wrote the paper, he was the co-supervisor of the project. SA prepared the project proposal, shared in data collection, did data analysis and wrote the paper, shared the consumables. AE did data analysis, wrote the paper, shared the consumables of the research. All authors have read and approved the final manuscript.

\section{Funding}

The authors received no financial support for doing this research, authorship, or publication of this article.

\section{Availability of data and materials}

Data are available on request. Authors may be contacted at the email: carcar.2009@yahoo.com (Dr.Gaafar Mahmoud)

\section{Declarations}

\section{Ethics approval and consent to participate}

Ethical approval was obtained from the Ethics Research Committee of National Ribat University (Ph.D/medical-lab/2015/no:1). Written consents were obtained from all patients participated in this study.

\section{Consent for publication}

Not applicable.

\section{Competing interests}

All authors declare that they have no financial relationships at present or had any in the previous years with any organizations that might have an interest in the submitted research.

\section{Author details}

'Department of Chemical Pathology, Faculty of Medical Laboratory Sciences, The National Ribat University, P.O. Box 55, Khartoum, Sudan. ${ }^{2}$ Department of Clinical Chemistry, Ribat University Hospital, Khartoum, Sudan. ${ }^{3}$ Department of Medicine and Endocrinology, Ribat University Hospital, Khartoum, Sudan. ${ }^{4}$ Department of Clinical Laboratory Sciences, College of Applied Medical Sciences, Taibah University, Medina, Kingdom of Saudi Arabia. ${ }^{5}$ Department of Medical Basic Sciences, Faculty of Applied Medical Sciences, University of Bisha, Bisha, Kingdom of Saudi Arabia.

\section{Received: 5 March 2021 Accepted: 12 May 2021}

Published online: 25 May 2021

\section{References}

Acharya AB, Thakur S, Muddapur MV, Kulkarni RD (2016) Tumor necrosis factor- $a$, interleukin- 4 and -6 in the serum of health, chronic periodontitis, and type 2 diabetes mellitus. J Indian Soc Periodontol 20:509-513. https://doi.org/10.4103/0972-124X.201694

Al-Ayed M, Alshaybari K, Alshehri D et al (2019) Obesity and childhood asthma in male schoolchildren in Saudi Arabia: Is there a role for leptin, interleukin-4, interleukin-5, and interleukin-21? Ann Saudi Med 39:295-301. https://doi.org/10.5144/0256-4947.2019.295

Arababadi MK, Mosavi R, Ravari A, Teimori H, Shahi GH (2012) Association of interleukin-4 polymorphisms with multiple sclerosis in southeastern
Iranian patients. Ann Saudi Med 32:127-130. https://doi.org/10.5144/ 0256-4947.2012.127

Balasubramanian SP, Azmy I, Higham SE et al (2006) Interleukin gene polymorphism and breast cancer: a case control study and systemic literature review. BMC Cancer 6:188. https://doi.org/10.1186/1471-2407-188

Cilensek I, Mankoc S, Petrovic MG, Petrovic D (2012) GSTT1 null genotype is a risk factor for diabetic retinopathy in Caucasians with type 2 diabetes, whereas GSTM1 null genotype might confer protection against retinopathy. Dis Markers 32:93-99. https://doi.org/10.3233/DMA-2011-0863

Ciulla TA, Amador AG, Zinman B (2003) Diabetic retinopathy and diabetic macular edema: pathophysiology, screening, and novel therapies. Diabetes Care 26:2653-2664. https://doi.org/10.2337/diacare.26.9.2653

Hebert HL, Veluchamy A, Torrance N, Smith BH (2017) Risk factors for neuropathic pain in diabetes mellitus. Pain 158:560-568. https://doi.org/10. 1097/j.pain.0000000000000785

Justiz Vaillant AA, Qurie A (2020) Treasure Island (FL): StatPearls Publishing. http://creativecommons.org/licenses/by/4.0/

Kasznicki J, Kosmalski M, Sliwinska A et al (2012) Evaluation of oxidative stress markers in pathogenesis of diabetic neuropathy. Mol Biol Rep 39:86698678. https://doi.org/10.1007/s11033-012-1722-9

Kundu D, Mandal T, Nandi M, Osta M, Bandyopadhyay U, Ray D (2014) Oxidative stress in diabetic patients with retinopathy. Ann Afr Med 13:41

Kuran G, Aslan H, Haytoğlu S, Özalp Yüreğir Ö, Tuğ Bozdoğan S (2019) IL-1RN VNTR, IL-2(-330), and IL-4 VNTR gene polymorphisms in patients with chronic rhinosinusitis with sinonasal polyposis. Turk J Med Sci 49:14111417. https://doi.org/10.3906/sag-1710-186

LaPorte SL, Juo ZS, Vaclavikova J et al (2008) Molecular and structural basis of cytokine receptor pleiotropy in the Interleukin-4/13 system. Cell 132:259-272. https://doi.org/10.1016/j.cell.2007.12.030

Madsen-Bouterse SA, Kowluru RA (2008) Oxidative stress and diabetic retinopathy: pathophysiological mechanisms and treatment perspectives. Rev Endocr Metab Disord 9:315-327. https://doi.org/10.1007/ s11154-008-9090-4

Maritim AC, Sanders RA, Watkins JB 3rd (2003) Diabetes, oxidative stress, and antioxidant: a review. J Biochem Mol Toxicol 17:24-38. https://doi.org/10. 1002/jbt.10058

Nakashima H, Miyake K, Inoue Y et al (2002) Association between IL-4 genotype and IL-4 production in the Japanese population. Genes Immun 3:107-109. https://doi.org/10.1038/sj.gene.6363830

Oyenihi AB, Ayeleso AO, Mukwevho E, Masola B (2015) Antioxidant strategies in the management of diabetic neuropathy. BioMed Res Int 2015:515042. https://doi.org/10.1155/2015/515042

Pang L, Lian X, Liu H, Zhang Y, Li Q, Cai Y, Ma H, Yu X (2020) Understanding diabetic neuropathy: focus on oxidative stress. Hindawi, Oxidative Medicine and Cellular Longevity Volume. 2020, Article ID 9524635, 13 pages. https://doi.org/10.1155/2020/9524635

Pasnoor M, Dimachkie MM, Kluding P, Barohn RJ (2013) Diabetic neuropathy part 1: overview and symmetric phenotypes. NIH Public Access, Neurol Clin 31:425-445. https://doi.org/10.1016/j.ncl.2013.02.004

Prabodha LBL, Sirisena ND, Dissanayake VHW (2018) Susceptible and prognostic genetic factors associated with diabetic peripheral neuropathy: a comprehensive literature review. Int J Endocrinol 2018:8641942. https:// doi.org/10.1155/2018/8641942

Pradhan P, Upadhyay N, Tiwari A, Singh LP (2016) Genetic and epigenetic modifications in the pathogenesis of diabetic retinopathy: a molecular link to regulate gene expression. New Front Ophthalmol 2:192-204. https://doi. org/10.15761/nfo.1000145

Rosenberger DC, Blechschmidt V, Timmerman H, Wolff A, Treede R-D (2020) Challenges of neuropathic pain: focus on diabetic neuropathy. Neural Transm 127:589-624. https://doi.org/10.1007/s00702-020-02145-7

Stamenkovic M, Lukic V, Suvakov S et al (2018) GSTM1-null and GSTT1-active genotypes as risk determinants of primary open angle glaucoma among smokers. Int J Ophthalmol 11:1514-1520. https://doi.org/10.18240/ijo. 2018.09.14.eCollection2018

Stoian A, Bsnescu C, BslaGa R, Moususianu A, Stoian M, Valeriu G. Moldovan, Voidszan S, Dobreanu M (2015) Influence of GSTM1, GSTT1, and GSTP1 polymorphisms on type 2 diabetes mellitus and diabetic sensorimotor peripheral neuropathy risk. Hindawi Publishing Corporation Disease Markers, Volume 2015, Article ID 638693, 10 pages. https://doi.org/10. $1155 / 2015 / 638693$ 
Themistocleous AC, Ramirez JD, Shillo PR et al (2016) The Pain in Neuropathy Study (PiNS): a cross-sectional observational study determining the somatosensory phenotype of painful and painless diabetic neuropathy. Pain 157:1132-1145. https://doi.org/10.1097/j.pain.0000000000000491

Tong YO, Ye JJ, Wang ZH et al (2013) Association of variable number of tandem repeat polymorphism in the IL-4 gene with ischemic stroke in the Chinese Uyghur population. Genet Mol Res 12:2423-2431. https://doi.org/ 10.4238/2013.May.13.2

Tsao C-H, Shiau M-Y, Chuang P-H, Chang Y-H, Hwang J (2014) Interleukin-4 regulates lipid metabolism by inhibiting adipogenesis and promoting lipolysis. J Lipid Res 55:385-397. https://doi.org/10.1194/jlr.M041392

Yeong YJ, Young YC, Jin BK (1927) Interleukin-4 and interleukin-13 exacerbate neurotoxicity of prothrombin kringle-2 in cortex in vivo via oxidative stress. Int J Mol Sci 2019:20. https://doi.org/10.3390/ijms20081927

Yue L, C Ryu, Munie M, Noorulla S, Rana S, Edwards P, Gao H, Qiao X (2018) Association of metformin treatment with reduced severity of diabetic retinopathy in type 2 diabetic patients. Hindawi. Journal of Diabetes Research, Volume 2018, Article ID 2801450, 8 pages. https://doi.org/10. 1155/2018/2801450

Završnik M, Letonja J, Makuc J, Šeruga M, Cilenšek I, Petrovič D: Interleukin-4 (IL4) -590C/T (rs2243250) gene polymorphism is not associated with diabetic nephropathy (DN) in Caucasians with type 2 diabetes mellitus (T2DM). Bosn J Basic Med Sci. 2018, 18:347-51. DOl: http://dx.doi. org/https://doi.org/10.17305/bjbms.2018.2688

Zhao Y, Zhu R, Wang D, Liu X (2019) Genetics of diabetic neuropathy: Systematic review, meta-analysis and trial sequential analysis. Ann Clin Trans Neurol 6:1996-2013. https://doi.org/10.1002/acn3.50892

\section{Publisher's Note}

Springer Nature remains neutral with regard to jurisdictional claims in published maps and institutional affiliations.

\section{Submit your manuscript to a SpringerOpen ${ }^{\circ}$ journal and benefit from:}

- Convenient online submission

- Rigorous peer review

- Open access: articles freely available online

- High visibility within the field

- Retaining the copyright to your article

Submit your next manuscript at $\boldsymbol{\nabla}$ springeropen.com 